July 2021

"Environmental Policy with Green Consumerism"

Stefan Ambec and Philippe De Donder 


\title{
Environmental Policy with Green Consumerism
}

\author{
Stefan Ambec* and Philippe De Donder ${ }^{\dagger \ddagger}$
}

July 2021

\begin{abstract}
We analyze environmental policy in a model where some consumers (dubbed green) derive warm glow from buying a good of a higher environmental quality, and where green firms differentiate products on their environmental quality to enjoy market power. For any given pollution level, emission taxes turn out to be less cost-effective than an emission standard because taxation always induces a higher wedge between the environmental qualities of products. By stark contrast, consumers prefer taxes to standards when the willingness to pay for greener goods is not too large. Also, the ability of green firms to exert market power makes the tax less attractive to green consumers. When the pollution level is endogenized via majority voting, both neutral and green consumers vote in favor of laxer standards and therefore pollution is higher compared to the case of non-differentiated products. By contrast, the majority chosen tax induces the efficient level of pollution. Green consumerism then reduces environmental protection with standards but not with taxes.
\end{abstract}

Key Words: environmental regulation, corporate social responsibility, green consumerism, product differentiation, tax, standard, green label, political economy.

JEL codes: D24, D62, Q41, Q42, Q48.

*Toulouse School of Economics, INRAE, University of Toulouse Capitole, 1 Esplanade de l'Université, 31 080 Toulouse Cedex 6, France. Email: stefan.ambec@tse-fr.eu

${ }^{\dagger}$ Toulouse School of Economics, CNRS, University of Toulouse Capitole, Toulouse, France. Email: philippe.dedonder@tse-fr.eu

${ }^{\ddagger}$ We thank participants to seminars and conferences held at EAERE 2019 (Manchester), IAERE 2020 (Brescia), CORE (Louvain-la-Neuve), TSE (Toulouse), ANU (Canberra), SCSE (Québec), and especially M. Dewatripont, J. Hindriks, G. Llobet, M. Price, J. Thisse and J. Tirole for their suggestions. We also thank Marie Philippe for excellent research assistance. This research has been supported by the TSE Energy and Climate Center and the H2020-MSCA-RISE project GEMCLIME-2020 GA No. 681228. We acknowledge funding from ANR under grant ANR-17-EURE-0010 (Investissements d'Avenir program). All errors and shortcomings are ours. 


\section{Introduction}

\subsection{Green consumerism, corporate social responsibility and envi- ronmental policies}

When firms and customers are only motivated by their self-interest, they tend to ignore their negative impact on the environment, which leads to excessive pollution and overexploitation of open-access natural resources such as water and clean air. This in turn calls for public intervention to fix, or at least mitigate, this market failure. This traditional view is contradicted by the many private initiatives to reduce the negative impacts of human activities on the environment. For instance, some consumers accept to pay a higher price in order to purchase more environmentally-friendly products. This phenomenon is sometimes referred to as 'green consumerism'. On the supply side, firms often reduce their emissions of pollutants and their use of natural resources beyond what is mandated by regulations. They engage in costly eco-labelling of their products and production processes. They endorse the so-called Corporate Social Responsibility (CSR) policy and code of conduct.

CSR is now very popular among managers and policy makers. It is part of most business school curricula. There is wide evidence that consumers care about CSR as many of them are willing to pay more for greener or fair trade products. The positive view of CSR and green consumerism contrasts with Friedman's famous criticism published in 1970 in The New York Times (Friedman, 1970). In an article provocatively entitled 'The Social Responsibility of Business is to Increase its Profits', Milton Friedman criticized CSR for being undemocratic. He argued that, with CSR, the businessman 'decides whom to tax by how much and for what purpose'. In a democratic society, 'the machinery must be set up to make the assessment of taxes and to determine through a political process the objectives to be served'.

Our objective is to go beyond Friedman's criticism and to better understand the interplay 


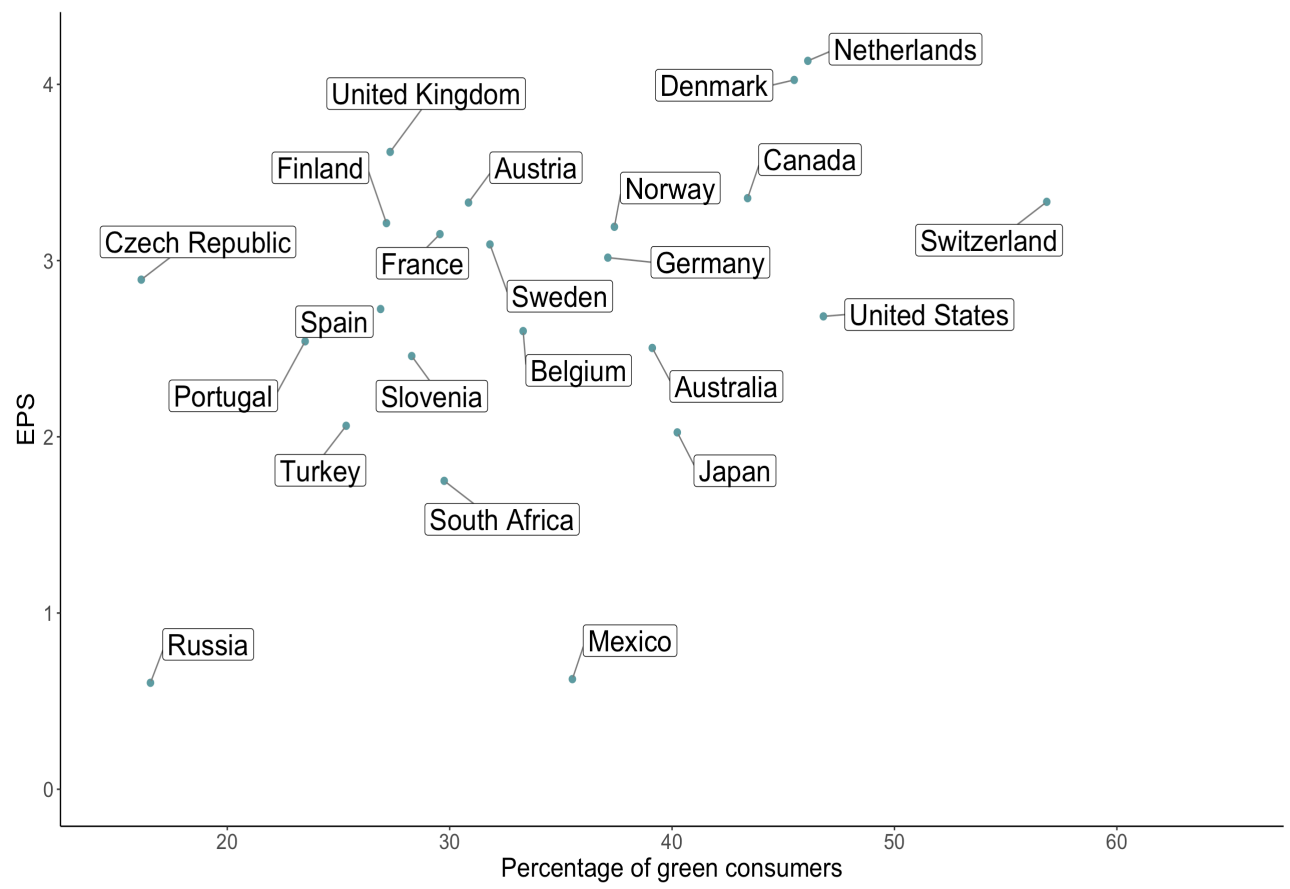

Figure 1: Green consumerism and environmental policy stringency

between "public" and "private" politics in the context of CSR. ${ }^{1}$ Before turning to our model, we provide some illustrative evidence of the complex relationship between green consumerism and environmental policies. The World Value Survey (WVS) asks respondents how willing they would be to pay much higher prices in order to protect the environment. The share of those answering that they were very or fairly willing is significant, ranging from 20 to 60 percent depending on the country, as reported on the horizontal axis of Figure 1. In this figure, we also plot the stringency of the environmental policies implemented in various countries, as measured by the Environmental Policy Stringency (EPS) index computed by the OECD. ${ }^{2}$ Figure 1 suggests that the relationship between the stringency of environmental policies and green consumerism is complex, the two being neither simple substitutes nor complements.

\footnotetext{
${ }^{1}$ In the words of Benabou and Tirole (2010, p.15), "While the invisible hand of the market and the more visible one of the state have been the objects of much research, we still know little about the decentralized correction of externalities and inequality."

${ }^{2}$ The computation of the EPS index is detailed in https://www.oecd.org/economy/greeneco/Howstringent-are-environmental-policies.pdf. We use 2010 data for both indices, corresponding to the most recent WVS, see: http://w.issp.orghome.
} 
To shed more light on this complex link, we develop a model incorporating social decisions taken democratically (through majority voting over either an environmental quality standard or an environmental tax), green consumerism (with a fraction of consumers deriving warm glow from buying a greener product) and CSR. We take Friedman's criticism on board by reconciling CSR with profit-maximization (with profit-maximizing firms producing the high quality good) in a context where social decisions are taken democratically. ${ }^{3}$

We model an economy with two types of citizens, dubbed neutral and green, who all consume one unit of a polluting good. While all consumers suffer in the same way from aggregate pollution, green consumers derive warm glow from their individual consumption decision. They value the higher environmental quality of the products they purchase compared to the mainstream ones. We call the intensity of this warm glow effect the level of green consumerism. A higher environmental quality means a less polluting production process or use of the product. Environmental quality does not affect the intrinsic service the product provides to consumers over its lifespan. The motive for supplying greener goods is pure profitmaximization: green firms bear the cost of higher environmental performance to move away from perfect competition and to exert some market power on green consumers. We allow the degree of competition to range from perfect competition (free entry of green good producers) to monopoly limit pricing (a monopoly green firm competing with a fringe of brown good producers).

Although the framework we develop is specific, several markets share its most important features. In the retail electricity market, surveys show that some consumers are willing to pay more for green energy (about 11-12\% more according to Krishnamurthy and Kriström, 2015). Ma and Burton (2016) provide experimental evidence suggesting that their motivation

\footnotetext{
${ }^{3}$ Benabou and Tirole (2010, p15) argue that "there are three possible understandings of corporate social responsibility: the adoption of a more long-term perspective, the delegated exercise of philanthropy on behalf of stakeholders, and insider-initiated corporate philanthropy. The latter two understandings build on individual social responsibility." Our approach is consistent with the second perspective, where "profit maximization and CSR are consistent." (Benabou and Tirole, 2010, p.11).
} 
is a "buy-in warm glow for carbon mitigation". Many retailers offer $100 \%$ green electricity contracts at a price premium through green certificates. Some of them highlight renewable energy sources in their advertising campaigns as a way to differentiate themselves from their competitors. When it comes to public policy, both quantity instruments (renewable portfolio standards) and price instruments (carbon taxes, feed-in tariffs) have been implemented. In the automobile industry, some car manufacturers such as Honda or Tesla have specialized in hybrid or electric vehicles. Hidrue et al. (2011) provide evidence that some consumers are willing to pay a price premium for electric vehicles (from $\$ 6000$ to $\$ 16000$ ). In the food retailing market, green labels such as organic food abound. As argued by Ambec and Lanoie (2008), going green is often a product differentiation strategy to escape competition and, thus, to exploit some market power on a niche of consumers. Some producers go beyond standards on pesticide or antibiotic use, a public policy alternative to the (non-mandatory) organic label. Pesticides are not only regulated through standards, they are often taxed to disincentivize their use. Both the standards and taxes on pesticides are collectively decided at the level of a country and/or local communities.

In accordance with these examples, we contrast two forms of public intervention: a standard on environmental quality and a tax on pollution. We first consider an arbitrary pollution target. A major difference between the two instruments is that the standard determines the quality of the brown good but not of the green one, which depends only on the green consumers' warm-glow intensity. This in turn means that a single good is produced if the warm glow/green consumerism intensity is small compared to the pollution target. By contrast, taxation affects the quality of both goods, which are always differentiated at equilibrium.

Comparing the two instruments from an efficiency perspective, we find that the standard dominates the tax because, regardless of the pollution reduction target, the wedge between environmental qualities is always higher with the tax than with the standard, leading to a higher gap between marginal abatement costs. Green consumerism then reverses the usual 
cost-efficiency advantage of the tax over the standard. ${ }^{4}$

We also compare the utility of both types of consumers with the two policy instruments. This comparison sheds light on the second main difference between them, with taxation generating welfare transfers between stakeholders. Neutral consumers are net contributors to the tax system when tax proceeds are redistributed in a lump sum way to all consumers. By contrast, green consumers receive a positive net transfer provided that the supply of green products is competitive enough, with firms capturing a larger proportion of tax proceeds, through their pricing behavior, when the market is less competitive. We then obtain that consumers prefer the tax to the standard except when the green consumers' taste for environmental quality is high enough. In particular, green consumers always prefer the tax when the degree of competition among green firms is high. Both neutral and green consumers like the larger wedge between the brown and green good quality levels induced by the tax, but for different reasons. Neutral consumers buy a lower priced version of the good and free-ride on the green consumers' less polluting choice. This free-riding effect offsets the fact that neutral consumers are net contributors to the tax system. Green consumers enjoy a higher warm-glow utility with more differentiated products induced by the tax. Note that green producers are able to capture a higher share of this warm-glow utility and of the tax revenue with more market power, explaining why green consumers might prefer a standard when the degree of competition is low enough. The bottom line is that both type of consumers prefer the less cost-effective instrument (the tax) except when the willingness to pay for green goods is high enough.

Next we endogenize the environmental target with each instrument. We adopt a political economy approach where citizens first vote over the instrument's level, with production and consumption decisions taking place later on. We characterize the preferred level of each

\footnotetext{
${ }^{4}$ Note that, in our framework, the two instruments are equally cost-efficient in reducing pollution in the absence of green consumers as a single quality good would then be produced.
} 
instrument starting with the standard. We find that product differentiation makes neutral consumers vote for a lower emission standard because of the free-riding effect. Furthermore, and counter-intuitively, green consumers vote for an even less stringent standard than neutral consumers. Indeed, while both types of consumer share the same benefit of a higher standard through less pollution, they differ on its cost. Unlike neutral consumers, green ones also lose some warm glow as the standard increases, an effect which is only partially compensated by a lower price, ${ }^{5}$ and induces them to prefer a lower standard than neutral consumers. We also examine the collective choice of the emission tax. We obtain that both types of consumers vote for the tax rate implementing the efficient aggregate level of pollution. However, the resulting environmental qualities are heterogeneous and, therefore, as already mentioned, the outcome is cost-inefficient.

Going back to Friedman's criticism on CSR, we then highlight that having some consumers "doing the right thing" by purchasing greener goods is not always welfare improving, even when firms maximize profit and the level of environmental protection is chosen democratically. In our setting, the conjunction of CSR with green consumerism leads to productive inefficiency and substandard policies.

\subsection{Related literature}

Our paper builds on the literature on self-regulation and corporate social responsibility (see Ambec and Lanoie, 2008, and Kitzmueller and Shimshack, 2012, for surveys). Most studies aim at assessing the profitability of voluntary environmental protection and CSR strategies. Some previous works have analyzed the interplay between environmental policies and firms' or consumers green behavior using different approaches. For instance, Fleckinger and Glachant (2011) analyze a game between a social-welfare maximizing regulator and a profit-maximizing

\footnotetext{
${ }^{5}$ Except with monopoly limit pricing, in which case the green producer extracts all the warm-glow utility, resulting in the same preferred standard for both types of consumers.
} 
firm with frictions in the regulation process. They show that self-regulation can be a firm's strategy to preempt more stringent future regulations. In the same vein, the Private Politics approach (Baron 2001, Heyes and Kapur, 2012, Daubanes and Rochet, 2019) assumes that CSR and environmental policies result from combined pressure from lobbies (firms) and NGOs (consumers/citizens). We depart from those studies by modeling explicitly the collective decision process that determines environmental policy. Other papers highlight that CSR might crowd-out donation and charity (Kotchen, 2006, Besley and Ghatak, 2007), or analyze price competition and product differentiation with green consumers (Eriksson, 2004, Conrad, 2005). However, they do not endogenize environmental regulations using a political economy approach. The paper closest to ours is Calveras et al. (2007) which also models green consumers with warm-glow preferences who vote on environmental regulations. They show that the presence of green consumers might lead to laxer regulations when a majority of voters free-ride on their contribution to the environment. We provide an even more negative view of green consumerism when such behavior is used by firms to obtain market power: all consumers (neutral and green) vote for a laxer minimal quality standard. Moreover, we compare policies instruments and we also analyze the political outcome when an environmental tax is implemented instead of an environmental standard.

Our paper also contributes to the literature comparing second-best policies, such as a tax and a standard in the case of environmental externalities. The trade-off between the two instruments do not arise because of asymmetric information on abatement cost (as in Weitzman, 1974, Ambec and Coria, 2021), or due to the heterogeneity of the pollution sources and damages (as in Fowlie and Muller 2019; Jacobsen 2013; Carson and LaRiviere 2018). Compared to this literature, we obtain that standards dominate taxes even without behavioral anomalies such as limited attention (Allcott et al. 2012) or temptation (Tsvetanov and Segerson 2014). ${ }^{6}$

\footnotetext{
${ }^{6}$ In the same vein, Bovenberg et al. (2008) study second-best policies designed to reduce deadweight loss
} 
Along the same line, Jacobsen et al. (2017) demonstrates the possible superiority of standards in a model of public good provision where agents differ in how much they value the total amount of public good, and where the cost of public good provision is convex. ${ }^{7}$ Agents who value more the good provide more of it, creating an inefficient wedge in the marginal cost of production. Our analysis goes further, as it endogenizes the amount of the environmental good offered by explicitly modeling its political determination. Others studies rely on imperfect competition models with vertical differentiation on environmental quality to compare policy instruments (e.g. Bansal and Gangopadhyay 2003). The paper closer to us in this field is Marini et al. (2020) who assume that brown and green firms have the same production costs which do not vary with the environmental quality of the product. In contrast to us, they obtain the counter-intuitive results that only the green good is provided when green consumerism is low, and that green consumerism degrades the environment by allowing brown firms to enter the market. Also, unlike us they do not compare and endogenize environmental policies.

Recent papers have investigated morally motivated consumers in economic framework with environmental externalities. Eichner and Pethig (2020) assume that some consumers are Kantians in the sense that they choose their consumption as if all others chose the same consumption as they do. By contrast, in our model, green consumers behave a la Nash, taking the other's consumption choices as given. ${ }^{8}$ Schmidt and Herweg (2021) also model a warm-glow utility but obtain that the price instrument dominates the quantity instrument in terms of material welfare, a result opposite to ours. This difference is due to their modeling from externalities and obtain numerically that standards may also be preferred to taxes, because of higher lump-sum compensation costs with the tax.

${ }^{7}$ This heterogeneity, unlike in our paper, drives the private contribution to the public good. Under our assumption of a unitary mass of agents, each agent's consumption decision has an infinitesimal impact on the total level of environmental protection and is then unaffected by how much agents care for this aggregate level. Our assumption is more in line with global pollution problems such as climate change.

${ }^{8}$ Cassin et al. (2021) study the impact of income inequality on environmental policy in the presence of green consumers. They obtain empirically an inverted J-shape relationship between the two. 
the quantity instrument as an emission trading scheme capping total emissions, so that any individual initiative to reduce emissions becomes ineffective since it is fully offset by the extra emissions from the others. The standard we model does not have this unfortunate feature.

Finally, recent papers have introduced environmentalism in growth models. Bezin (2019) studies the trade-off between growth and environmental preservation in a setting where green preferences are formed through cultural transmission. ${ }^{9}$ Aghion et al. (2020) analyzes the incentives to innovate in green technologies to soften competition when consumers care about the carbon footprint of their product. They highlight a complementarity between the level of competition and green consumerism in fostering green innovation. In our model, the degree of competition is orthogonal to the choice of environmental quality. Market power increases the price of the green good but not does not reduce its carbon footprint. As a result, unlike Aghion et al. (2020), competition and green consumerism are substitute in reducing pollution because (i) green consumers vote for laxer standards than neutral consumers, (ii) the higher is the competition, the laxer is the standard chosen by green consumers.

The structure of the paper is as follows. The next section presents our setting. Section 3 investigate the implementation of a targeted pollution level with emission standard (Section 3.1) or emission tax (Section 3.2) before comparing the two outcomes (Section 3.3). Section 4 endogenizes the target reached with each policy instrument through collective choice of standard (Section 4.1) and then tax (Section 4.2). Section 5 concludes. The more convoluted proofs are relegated to an appendix.

\footnotetext{
${ }^{9}$ Bezin (2015) analyses an overlapping generations model of environmental externalities and capital accumulation where private contributions to environmental quality are motivated by a desire to socialize others into environmental attitudes.
} 


\section{The setting}

We consider a good whose production or consumption generates environmental externalities, typically pollution. We index pollution abatement by the continuous variable $x$ that we call the good's environmental quality. A higher value of $x$ reflects, for instance, the use of a cleaner source of energy to produce electricity, a less polluting car, food grown with less pesticide or water, a manufactured product that can be more easily recycled, etc. Alternatively, one can see $x$ as a 'public good' contribution to society in the corporate social responsibility (CSR) sense, e.g. better working conditions, transparency, banning of child labor, investment in education, infrastructure, etc. The cost of supplying one unit of the good with environmental quality $x$ is denoted $c(x)$ where $c($.$) is an increasing, twice differentiable and convex function$ of $x$, with $c(0)=0$ and $c^{\prime}(0)=0$ (to guarantee interior solutions).

On the demand side, we consider a unitary mass of consumers who are divided into two types, green and neutral, with respective shares $\alpha$ and $1-\alpha$ with $0<\alpha<1$. The types are denoted by subscripts $g$ and $n$, respectively. All consumers obtain the same private value $v$ from consuming one unit of the good, regardless of its environmental quality. Both types of consumers also enjoy the same benefit $b(X)$ from the average environmental quality $X$, which is the level of environmental protection in the economy. ${ }^{10}$ The function $b($.$) is strictly$ increasing, twice differentiable and strictly concave: $b^{\prime}(x)>0$ and $b^{\prime \prime}(x)<0$. Neutral consumers rationally do not care directly about the pollution generated by their own purchase decision: they do not value the environmental quality of the good they consume, since their own consumption does not impact the average environmental quality in the economy. Their utility when they purchase the good at price $p$ is $v-p+b(X)$. By contrast, green consumers enjoy a 'warm glow' from contributing to environmental protection above the lower environmental quality provided by the market that we denote $x_{0} \cdot{ }^{11}$ Let $\omega$ be the green consumers'

\footnotetext{
${ }^{10}$ Note that average and total environmental qualities are equal with a unitary mass of consumers.

${ }^{11}$ Assuming rather that green consumers care more about environmental protection $X$ than neutral con-
} 
willingness to pay for every environmental quality above $x_{0}$. The parameter $\omega$ is hereafter referred to as the level of green consumerism while $\alpha$ is the share of green consumerism. Green consumers' utility when purchasing a good of environmental quality $x$ at price $p$ is $v-p+\omega\left(x-x_{0}\right)+b(X)$.

On the supply side, a competitive industry is supplying the "brown" version of the good with environmental quality $x_{0}$. Perfect competition drives down profit to zero. We assume that some firms can supply higher environmental quality than the standard, $x_{1}>x_{0}$. We are agnostic as to the degree of competition among firms supplying the green version of the good. The intensity of competition is captured by a parameter $\theta$ ranging from zero for perfect competition to one for monopoly limit pricing. For $0<\theta \leq 1$, green firms can exert some market power from providing a greener version of the good (called the green good). ${ }^{12}$

We now investigate the impact of environmental policies for a given pollution target $X$. We consider sequentially an environmental quality standard and a pollution tax. We then compare the two instruments from a welfare perspective. The timing of the decisions runs as follows. First, firms set simultaneously their prices and environmental quality given the policy enacted. Second, consumers make their purchase decisions.

\section{Economic outcome}

In this section, we study the setting of an environmental policy imposed on all firms in order to achieve a given aggregate level of emissions $X$. We examine an environmental quality standard $x_{0}$ in Section 3.1., and a pollution tax $\tau$ in Section 3.2. We compare the welfare impact of both instruments in Section 3.3.

sumers would not induce them to consume higher quality goods than the latter, with a unitary mass of consumers, unlike with warm glow.

${ }^{12}$ This assumption can be justified by the ownership of a specific technology or the long-term development of a reputation for being greener. For instance, the firm is the only one that can credibly commit to issue a label of better environmental quality. 


\subsection{Environmental standard}

Competition among producers of the good with minimal quality $x_{0}$ drives down its equilibrium price towards its costs, $p_{0}=c\left(x_{0}\right)$. Some firms might supply a higher environmental quality version of the good if it is profitable to do so. Green firms supply the quality $x_{1}>x_{0}$ at price $p_{1}>p_{0}$. Green consumers buy green goods whenever ${ }^{13}$

$$
v-p_{1}+\omega\left(x_{1}-x_{0}\right)+b(X) \geq v-p_{0}+b(X) .
$$

We first assume that $x_{1}>x_{0}$ and compute the equilibrium price depending on the degree of competition. We then check that green firms make a positive profit, and that $x_{1}>x_{0}$, at that price. If it is not the case, then they offer $x_{1}=x_{0}$ for $p_{1}=p_{0}$.

Let us consider the extreme cases of perfect and no competition on the market for the green good. Under perfect competition, a price-taker firm charges $p_{1}=c\left(x_{1}\right)$. Under monopoly, the price-maker firm chooses the maximum price compatible with green consumers buying quality $x_{1}$ rather than $x_{0}-$ i.e., $p_{1}=c\left(x_{0}\right)+\omega\left(x_{1}-x_{0}\right)$. In the more general case of a degree of competition $\theta \in[0,1]$ varying between no market power $(\theta=0)$ and full market power $(\theta=1)$, the price of the green good is:

$$
p_{1}=\theta\left[c\left(x_{0}\right)+\omega\left(x_{1}-x_{0}\right)\right]+(1-\theta) c\left(x_{1}\right) .
$$

A green good producer's profit per unit sold is then

$$
\begin{aligned}
\pi & =p_{1}-c\left(x_{1}\right) \\
& =\theta\left[\omega\left(x_{1}-x_{0}\right)+c\left(x_{0}\right)-c\left(x_{1}\right)\right],
\end{aligned}
$$

\footnotetext{
${ }^{13}$ We make the simplifying assumption that green consumers buy the green good when they are indifferent between the brown and green ones.
} 
where we have used the one-to-one relationship between price and quality defined in (1). Maximizing $\pi$ with respect to $x_{1}$, we obtain:

$$
\frac{\partial \pi}{\partial x_{1}}=\theta\left(\omega-c^{\prime}\left(x_{1}\right)\right)
$$

so that the profit-maximizing quality level, denoted by $x_{1}^{S}$ (where the superscript $S$ denotes the fact that firms are constrained by a standard) is such that ${ }^{14}$

$$
c^{\prime}\left(x_{1}^{S}\right)=\omega
$$

regardless of the degree of competition $\theta$. Green firms choose environmental quality to equate the marginal cost of providing a higher quality with the marginal benefit to the firm (through a larger price), which is equal to the willingness to pay for environmental quality $\omega{ }^{15}$ The corresponding price for a degree of competition $\theta$ is given by

$$
p_{1}^{S}=\theta\left[\omega\left(x_{1}^{S}-x_{0}\right)-\left[c\left(x_{1}^{S}\right)-c\left(x_{0}\right)\right]\right]+c\left(x_{1}^{S}\right) .
$$

Under perfect competition, $\theta=0$ in (3) so that the price equals marginal cost $p_{1}^{S}=c\left(x_{1}^{S}\right)$. Under monopoly (limit) pricing, $\theta=1$ in (3) and therefore $p_{1}^{S}=c\left(x_{0}\right)+\omega\left(x_{1}^{S}-x_{0}\right)$, so that the green firm captures all the green consumer surplus created by the warm glow effect of consuming a greener-than- $x_{0}$ product. When $0<\theta<1$, green firms capture only a fraction of this surplus.

We now show that the environmental quality $x_{1}^{S}$ is profitable for every $\theta>0 .{ }^{16}$ By convexity of the cost function, $x_{1}^{S}>x_{0}$ implies $c^{\prime}\left(x_{1}^{S}\right)\left(x_{1}^{S}-x_{0}\right)>c\left(x_{1}^{S}\right)-c\left(x_{0}\right)$. The last

\footnotetext{
${ }^{14}$ We concentrate on interior solutions since $c^{\prime}(0)=0$.

${ }^{15}$ Note from (2) that $x_{1}^{S}=c^{\prime-1}(\omega)$ does not depend on $x_{0}$, but increases with $\omega$ (since the cost function is convex).

${ }^{16}$ Profits are nil for green firms when $\theta=0$.
} 
inequality combined with (2) leads to $\omega\left(x_{1}^{S}-x_{0}\right)-\left[c\left(x_{1}^{S}\right)-c\left(x_{0}\right)\right]>0$, which given (3) shows that $p_{1}^{S}>c\left(x_{1}^{S}\right)$ when $\theta>0$.

When $x_{1}^{S}>x_{0}$ so that two environmental qualities are provided, neutral consumers buy the good with quality $x_{0}$ while green consumers buy the good with quality $x_{1}^{S}$. To achieve the environmental protection target $X=\alpha x_{1}^{S}+(1-\alpha) x_{0}$, given (2), the implemented standard $x_{0}^{S}$ must be:

$$
x_{0}^{S}=\frac{X-\alpha c^{-1}(\omega)}{1-\alpha} .
$$

Combining (2) with (4) shows that $x_{1}^{S}>x_{0}^{S}$ when $\omega>c^{\prime}(X)$. Hence products are differentiated on environmental quality if the warm-glow effect captured by the parameter $\omega$ is higher than the marginal cost of the environmental protection target $c^{\prime}(X)$. In the polar case where $\omega \leq c^{\prime}(X)$, no firms supply greener goods and thus the standard is the targeted environmental quality level $x_{0}^{S}=X$. We then obtain the following proposition.

Proposition 1 With a standard, a green version of the good with environmental quality $x_{1}^{S}=$ $c^{-1}(\omega)$ is supplied if $\omega>c^{\prime}(X)$. Otherwise, products are homogeneous with environmental quality $X$.

When the level of green consumerism $\omega$ is high enough, the demand for green goods induces some firms to differentiate their product by supplying a greener version. This version is charged at marginal cost under perfect competition, that is when $\theta=0$. In the case where $\theta>0$, production differentiation on environmental quality is a strategy for green firms to move away from perfect competition. They earn profits by extracting a share of the green consumers' willingness to pay for green goods. This share is increasing with $\theta$. When $\theta=1$, the monopoly captures it all as shown in (3). 


\subsection{Environmental tax}

We now move to another policy instrument to mitigate environmental externalities: a tax on pollution. We denote by $e$ the pollution emitted in the absence of any pollution abatement effort by firms, namely when they produce a good of quality $x=0$. Environmental quality $x$ then corresponds to the reduction in polluting emissions from that point. Pollution is taxed at a linear rate $\tau$. The total cost of supplying one unit of the product with environmental performance $x$ is $c(x)+\tau(e-x)$. The brown good producers choose the value of $x$ that minimizes their cost given the price of their product $p_{0}$. The environmental quality they choose is denoted by $x_{0}^{\tau}$ and satisfies the following first-order condition:

$$
\tau=c^{\prime}\left(x_{0}^{\tau}\right)
$$

where the marginal cost of environmental quality equals the tax rate. The competitive price per unit of product is defined by the zero-profit condition:

$$
p_{0}^{\tau}=c\left(x_{0}^{\tau}\right)+\tau\left(e-x_{0}^{\tau}\right)
$$

As in Section 3.1, the price $p_{1}$ of the green version of the good depends on the degree of competition among green firms captured by the parameter $\theta$. Under perfect competition,

the price is equal to the marginal cost which includes the tax bill: $p_{1}^{\tau}=c\left(x_{1}\right)+\tau\left(e-x_{0}^{\tau}\right)$. Under limit pricing, the monopoly charges the maximal price that makes green consumers buy quality $x_{1}$, which is $p_{1}^{\tau}=\omega\left(x_{1}-x_{0}\right)+p_{0}^{\tau}=\omega\left(x_{1}-x_{0}\right)+c\left(x_{0}^{\tau}\right)+\tau\left(e-x_{0}^{\tau}\right)$, where the last equality is due to (6). More generally, with a degree of competition $\theta \in[0,1]$, the price of the green good is:

$$
p_{1}^{\tau}=\theta\left[\omega\left(x_{1}-x_{0}\right)+c\left(x_{0}^{\tau}\right)+\tau\left(e-x_{0}^{\tau}\right)\right]+(1-\theta)\left[c\left(x_{1}\right)+\tau\left(e-x_{1}\right)\right],
$$


with $x_{0}^{\tau}$ and $p_{0}^{\tau}$ defined by (5) and (6). The profit per unit of the green good with environmental performance $x_{1}$ is:

$$
\pi=p_{1}^{\tau}-c\left(x_{1}\right)-\tau\left(e-x_{1}\right)=\theta\left[\omega\left(x_{1}-x_{0}^{\tau}\right)+c\left(x_{0}^{\tau}\right)-c\left(x_{1}\right)+\tau\left(x_{1}-x_{0}^{\tau}\right)\right],
$$

where the last equality is obtained by substituting $p_{1}^{\tau}$ as defined by (7). Differentiating $\pi$ with respect to $x_{1}$ yields:

$$
\frac{\partial \pi}{\partial x_{1}}=\omega-c^{\prime}\left(x_{1}\right)+\tau
$$

so that profit is maximized at a quality level $x_{1}^{\tau}$ satisfying the following first-order condition:

$$
\tau+\omega=c^{\prime}\left(x_{1}^{\tau}\right)
$$

Environmental performance increases profits through two channels: higher revenue (thanks to a larger price made possible by the green consumers' preference for greener goods) and lower tax paid. The best green strategy equalizes marginal cost to the sum of the green consumers' willingness to pay and the tax rate. Green firms choose $x_{1}^{\tau}=c^{\prime-1}(\omega+\tau)$ and charge $p_{1}^{\tau}$ defined in (7). The following proposition, proved in Appendix A, shows that green firms' profit is always positive when they choose $x_{1}=x_{1}^{\tau} \cdot{ }^{17}$

Proposition 2 With a tax, a green version of the good is supplied with environmental quality $x_{1}=x_{1}^{\tau}>x_{0}^{\tau}$ for all $\omega>0$.

Proposition 2 implies that, with a tax, products are differentiated on their environmental quality as long as $\omega>0$. By contrast, with a standard, as shown in Section 3.1, products are homogeneous with same environmental quality $X$ when $\omega$ is low. The willingness to

\footnotetext{
${ }^{17}$ Provided of course that consumers' willingness to pay is high enough to compensate for the tax paid: $v \geq p_{0}^{\tau}$ and $v+\omega\left(x_{1}^{\tau}-x_{0}^{\tau}\right) \geq p_{1}^{\tau}$.
} 
pay for environmental quality must be high enough to induce a supply of environmental quality above the minimal quality standard. When it is the case, the environmental qualities implemented with each instrument differ for the same average quality target $X$. Indeed a fundamental difference between the environmental tax and the standard is their impact on the environmental performance of the green product. In Section 3.1, we have shown that the standard $x_{0}$ has no direct impact on the level of environmental quality embedded in the green good $x_{1}^{S}$, see (2). The value of the standard only affects the decision whether or not to supply a greener good through $p_{1}$. By contrast, the tax impacts directly the green good's environmental performance $x_{1}^{\tau}$ as shown in (9). A higher tax increases both environmental performances $x_{0}^{\tau}$ and $x_{1}^{\tau}$ while a higher standard $x_{0}$ does not change $x_{1}^{S}$ as long as supplying the green good is profitable. ${ }^{18}$

With the same environmental target $X$, it is easy to rank the environmental qualities provided under both instruments. By (2) and (9), we have $x_{1}^{\tau}>x_{1}^{S}$ whenever $\tau>0$. The environmental quality of the green good is always higher with the tax because reducing the tax bill provides another motive for increasing environmental quality. Now, under the same average quality $X=\alpha x_{1}^{S}+(1-\alpha) x_{0}^{S}=\alpha x_{1}^{\tau}+(1-\alpha) x_{0}^{\tau}, x_{1}^{\tau}>x_{1}^{S}$ implies $x_{0}^{\tau}<x_{0}^{S}$. Hence, the tax implements the same environmental target $X$ with more dispersed qualities in the sense that $x_{0}^{\tau}<x_{0}^{S}<x_{1}^{S}<x_{1}^{\tau}$.

\subsection{Comparison of instruments}

We now compare the performance of the two instruments for a given environmental target $X$. We will consider sequentially two metrics for this comparison. First, we focus on the consumers' material welfare by ignoring the warm-glow effect. Doing so, we follow the canonical

\footnotetext{
${ }^{18}$ Note that, although both environmental qualities $x_{0}^{\tau}$ and $x_{1}^{\tau}$ depend on the tax rate, the incremental marginal cost $c^{\prime}\left(x_{1}^{\tau}\right)-c^{\prime}\left(x_{0}^{\tau}\right)$ does not. More precisely, the wedge between marginal costs of production always equals the green consumers' willingness to pay for environmental quality $\omega$ at equilibrium, namely $c^{\prime}\left(x_{1}^{\tau}\right)-c^{\prime}\left(x_{0}^{\tau}\right)=\omega$. This productive inefficiency of environmental taxation increases with the level of green consumerism $\omega$.
} 
approach first proposed by Hammond (1988) and Harsanyi (1995) who advocate to exclude all external preferences, even benevolent ones, when computing a social welfare function. This means that we "launder" the green consumers' preferences by assuming away the warm-glow part of their utility. ${ }^{19}$ As we show in section 3.3.1, maximizing material welfare for any given level of aggregate pollution $X$ corresponds to minimizing the cost of achieving this level, a pure efficiency approach. Second, we look at what instrument consumers would prefer to use to reach any given pollution level $X$. In that comparison, we of course include warm-glow as part of the green consumers' utility.

\subsubsection{Material Welfare}

Material welfare is the sum of the consumers' surplus (without the warm-glow effect), firms' profit, the benefit from pollution reduction, and the revenue from taxing pollution. When products are homogeneous in their environmental quality, which only occurs with a standard when $\omega \leq c^{\prime}(X)$, material welfare is $v-p_{0}-b(X)=v-c(X)-b(X)$, where the last equality is due to perfect competition which implies $p_{0}=c(X)$. Under product differentiation, green consumers buy the good with quality $x_{1}^{S}>x_{0}^{S}$ at price $p_{1}^{S}$ while the neutral ones buy the brown good $x_{0}^{S}$ at price $p_{0}^{S}$. Given the respective proportions $\alpha$ and $1-\alpha$ in the economy, material welfare is:

$$
v-\alpha p_{1}^{S}-(1-\alpha) p_{0}^{S}+b(X)+\alpha \pi_{1}^{S}
$$

\footnotetext{
${ }^{19}$ See Goodin (1986) for a description of the various grounds for laundering preferences. More specifically, Benabou and Tirole (2010, p.15) write "We saw that prosocial behaviour by investors, consumers and workers is driven by a complex set of motives: intrinsic altruism, material incentives (defined by law and taxes) and social- or self-esteem concerns. (...) The pursuit of social- and self-esteem per se is a zero-sum game" which may then call for laundering the preferences of these agents. For instance, "The buyer of a hybrid car feels and looks better, but makes his neighbours (both buyers and non-buyers of hybrid cars) feel and look worse-a 'reputation stealing' externality" (Benabou and Tirole, 2010, p.6).
} 
with $p_{0}=c\left(x_{0}\right), X=\alpha x_{1}^{S}+(1-\alpha) x_{0}^{S}$ and $\pi_{1}^{S}=\theta\left[\omega\left(x_{1}^{S}-x_{0}\right)+c\left(x_{0}^{S}\right)-c\left(x_{1}^{S}\right)\right]$ with a standard, and,

$$
v-\alpha p_{1}^{\tau}-(1-\alpha) p_{0}^{\tau}+b(X)+\alpha \pi_{1}^{\tau}+\tau\left[\alpha\left(e-x_{1}^{\tau}\right)+(1-\alpha)\left(e-x_{0}^{\tau}\right)\right]
$$

with $X=\alpha x_{1}^{\tau}+(1-\alpha) x_{0}^{\tau}$ and $\pi_{1}^{\tau}$ is defined in (8) with the tax.

Substituting the prices defined in (3), (6) and (7) into (10) and (11), we obtain a material welfare of:

$$
W\left(x_{1}^{j}, x_{0}^{j}\right)=v-\alpha c\left(x_{1}^{j}\right)-(1-\alpha) c\left(x_{0}^{j}\right)+b(X)
$$

for each instrument $j=S, \tau$. Hence the comparison of welfare is reduced to the comparison of the cost $\alpha c\left(x_{1}^{j}\right)+(1-\alpha) c\left(x_{0}^{j}\right)$ of achieving the target $X$ for each instrument $j=S, \tau$.

If $\omega \leq c^{\prime}(X)$, we know from Propositions 1 and 2 that the green good is not supplied with the standard while it is with the tax. The welfare is thus $v-c(X)+b(X)$ with the standard and $v-\alpha c\left(x_{1}^{\tau}\right)+(1-\alpha) c\left(x_{0}^{\tau}\right)+b(X)$ with the tax. The standard dominates because $c(X)<$ $\alpha c\left(x_{1}^{\tau}\right)+(1-\alpha) c\left(x_{0}^{\tau}\right)$ with $X=\alpha x_{1}^{\tau}+(1-\alpha) x_{0}^{\tau}$ due to the convexity of the cost function. If $\omega>$ $c^{\prime}(X)$, the green good is supplied with both instruments, although with different environmental qualities. Given the material welfare levels defined in (12), the standard dominates the tax if and only if $\alpha c\left(x_{1}^{S}\right)+(1-\alpha) c\left(x_{0}^{S}\right)<\alpha c\left(x_{1}^{\tau}\right)+(1-\alpha) c\left(x_{0}^{\tau}\right)$. We show in Appendix B that it is indeed the case due to the convexity of the cost function. We thus established the following proposition.

Proposition 3 The standard implements any environmental target $X$ at lower cost and with higher material welfare than the tax.

Even if the two instruments implement the same level of environmental protection, the tax does so with a higher wedge between the two environmental qualities supplied by the 
market $x_{0}$ and $x_{1}$ and, therefore, abatement costs are higher. In this sense, the tax is less cost-efficient (or cost-effective) than the standard for any target $X$.

The degree of competition does not impact the comparison between the two instruments when using cost-efficiency or material welfare. However, competition affects the allocation of material welfare between consumers and firms, with green firms extracting a higher share of green consumers' utility when $\theta$ increases.

\subsubsection{Utility}

In this section, we investigate which of the two instruments is preferred by consumers to reach

any given pollution level $X$. We denote by $U_{i}^{S}\left(x_{0}^{S}, x_{1}^{S}\right)$ the utility attained by a consumer of type $i=n, g$ when the standard $x_{0}^{S}$ is enacted, and a green good of quality $x_{1}^{S}$ is provided.

Under the standard, when $\omega \leq c^{\prime}(X)$, the goods consumed exhibit the same environmental quality $x_{0}=X$. Therefore the utility of the two types of consumers, neutral and green, is the same:

$$
U_{n}^{S}(X, X)=U_{g}^{S}(X, X)=v-c(X)+b(X)
$$

When $\omega>c^{\prime}(X)$, products are differentiated with two environmental qualities $x_{0}^{S}$ and $x_{1}^{S}$. With the prices $p_{0}=c\left(x_{0}^{S}\right)$ and $p_{1}^{S}$ defined in (3), we obtain:

$$
\begin{aligned}
& U_{n}^{S}\left(x_{0}^{S}, x_{1}^{S}\right)=v-c\left(x_{0}^{S}\right)+b(X), \\
& U_{g}^{S}\left(x_{0}^{S}, x_{1}^{S}\right)=v+(1-\theta) \omega\left[x_{1}^{S}-x_{0}^{S}\right]-\theta c\left(x_{0}^{S}\right)-(1-\theta) c\left(x_{1}^{S}\right)+b(X),
\end{aligned}
$$

where $x_{1}^{S}$ and $x_{0}^{S}$ are defined in (2) and (4) respectively and $X=\alpha x_{1}^{S}+(1-\alpha) x_{0}^{S}$. With perfect competition $(\theta=0)$, green consumers enjoy the full extent of their warm glow and pay a price equal to the green good's cost. As $\theta$ increases, green firms capture a larger fraction 
of this warm glow. With monopoly (limit) pricing $(\theta=1)$, green firms capture all the warm glow, and green consumers have the same utility as neutral ones.

With the tax, we assume that tax proceeds are redistributed to the consumers in a lumpsum way. Since $\tau\left(e-x_{1}^{\tau}\right)$ and $\tau\left(e-x_{0}^{\tau}\right)$ are collected on the green and brown products respectively, which are in proportion $\alpha$ and $1-\alpha$, each consumer gets back $R=\alpha \tau\left(e-x_{1}^{\tau}\right)+$ $(1-\alpha) \tau\left(e-x_{0}^{\tau}\right)=\tau(e-X)$, where the last equality is due to the fact that $X=\alpha x_{1}^{\tau}+(1-\alpha) x_{0}^{\tau}$. Hence, with the prices defined in (6) and (7), the utilities are:

$$
\begin{aligned}
U_{n}^{\tau}\left(x_{0}^{\tau}, x_{1}^{\tau}\right)= & v-c\left(x_{0}^{\tau}\right)+b(X)-\alpha \tau\left[x_{1}^{\tau}-x_{0}^{\tau}\right] \\
U_{g}^{\tau}\left(x_{0}^{\tau}, x_{1}^{\tau}\right)= & v+(1-\theta) \omega\left[x_{1}^{\tau}-x_{0}^{\tau}\right]-\theta c\left(x_{0}^{\tau}\right)-(1-\theta) c\left(x_{1}^{\tau}\right)+b(X) \\
& +\tau\left[\theta x_{0}^{\tau}+(1-\theta) x_{1}^{\tau}-X\right]
\end{aligned}
$$

with $x_{0}^{\tau}$ and $x_{1}^{\tau}$ defined in (5) and (9) respectively. The last terms in the right-hand side of both utilities are the net transfers due to the pollution tax. Since the standardized good is more taxed than the green good, neutral consumers pay more tax than the refunded revenue, with a net negative transfer equal to $\alpha \tau\left[x_{1}^{\tau}-x_{0}^{\tau}\right]$. The net transfer received by green consumers decreases with the degree of market power $\theta$. Under perfect competition $\theta=0$, each green consumer obtains a net positive transfer equal to $\tau(1-\alpha)\left[x_{1}^{\tau}-x_{0}^{\tau}\right]$. At the polar extreme (monopoly limit pricing), they end up with the same negative transfer as neutral consumers.

To be able to compare utilities, we introduce the following assumption of linear marginal costs, which guarantees that $\tau$ has the same impact on both qualities $x_{0}^{\tau}$ and $x_{1}^{\tau} \cdot{ }^{20}$

\section{Assumption 1 Let $c(x)=\gamma \frac{x^{2}}{2}$.}

We prove the following proposition in Appendix $\mathrm{C}$ (where the thresholds are explicitly defined in (40) and (44)).

\footnotetext{
${ }^{20}$ Indeed Assumption 1 implies $c^{\prime}(x)=\gamma x$ and, therefore $x_{0}^{\tau}=\tau / \gamma$ and $x_{1}^{\tau}=(\tau+\omega) / \gamma$ so that an increase in $\tau$ has the same impact on $x_{0}^{\tau}$ and $x_{1}^{\tau}$.
} 
Proposition 4 Assume that Assumption 1 holds and that consumers compare a tax and a standard that both result in the same aggregate environmental protection level $X$.

(a) All consumers prefer the tax to the standard, except when $\omega$ is large enough and, in the case of green consumers, when $\theta$ is large enough as well. For both consumer types, a necessary condition to prefer the standard to the tax is that the standard generates differentiated goods.

(b) The threshold value of $\omega$ above which a standard is preferred is increasing with $X$ for both types of consumers.

(c) This threshold is decreasing with $\theta$ for green consumers,

(d) This threshold is larger for green than for neutral consumers if $\theta<1$, and equal if $\theta=1$.

To prove Proposition 4 we consider successively two cases. First, when $\omega \leq c^{\prime}(X)$, products are homogeneous with environmental quality $X$ under the standard while they are differentiated with qualities $x_{0}^{\tau}<X<x_{1}^{\tau}$ with the tax. The brown version of the good being of lower environmental quality with the tax than the standard $X$, it is also cheaper. This price effect makes neutral consumers prefer the tax despite the fact that they are net tax contributors. Green consumers enjoy an even higher utility with the tax than neutral consumers since they always have the option to buy the brown good. On the other hand, both types of consumers have the same utility under the standard. Hence, if the neutral consumers prefer the tax to the standard, so do the green consumers.

Second, if $\omega>c^{\prime}(X)$, products of heterogeneous environmental quality are supplied both with the tax and with the standard. Observe first that, as $\omega$ increases, green consumers demand a higher quality good, so that an exogenous value of $X$ can be obtained with either a lower value of the standard $x_{0}^{S}$ or of the $\operatorname{tax} \tau$. Hence, neutral consumers benefit from a larger value of $\omega$ both under a tax and under a standard. At the same time, the net payment 
they make under a tax increases with the quality difference between the two goods, $x_{1}^{\tau}-x_{0}^{\tau}$, which itself increases with $\omega$. As a consequence, they favor less the tax system as $\omega$ increases, and we show in Appendix $\mathrm{C}$ that they start favoring the standard once $\omega$ reaches a threshold (given by (40)).

As for green consumers, equation (17) shows that they receive a positive net tax transfer (equal to $\left.(1-\alpha-\theta)\left(x_{1}^{\tau}-x_{0}^{\tau}\right)\right)$ provided that $\theta$ is low enough. We then obtain that they always prefer the tax to the standard when the market is sufficiently competitive (i.e., $\theta$ low enough). When $\theta$ is large, their utility increases faster with $\omega$ under the standard than under the tax. Note that this is true even though the warm glow effect is larger with the tax than with the standard (since the gap between both qualities provided is larger with the tax than with the standard). We show in Appendix $\mathrm{C}$ that green voters favor the standard once $\omega$ reaches a threshold (given by (44)). This threshold is larger than the corresponding one for neutral consumers, confirming that green voters have a stronger relative preference for a tax than neutral voters.

We then obtain that a less competitive green market (i.e., a higher value of $\theta$ ) decreases the threshold value of $\omega$ above which green voters prefer the standard to the tax. This is due to the fact that the green firms obtain a higher share of the net tax balance and of the warm-glow utility as $\theta$ increases, rendering the tax less attractive to green consumers. Under the extreme case of monopoly limit pricing, the green firm captures all the warm-glow utility and green consumers end up with the same utility than the neutral ones.

We also obtain that the threshold value of $\omega$ above which consumers prefer the standard increases with $X$, for both types of consumers. This is because the tax increases both $x_{0}$ and $x_{1}$ while the standard leaves $x_{1}$ unchanged. Therefore, to achieve a higher target $X$, the brown quality $x_{0}$ has to increase more with the standard than with the tax, increasing its price and making the standard less attractive for neutral consumers. For the green consumers, increasing $X$ with $\omega$ constant reduces their warm glow utility $\omega\left[x_{1}-x_{0}\right]$ with the standard as 
$x_{0}^{S}$ increases while $x_{1}^{S}=c^{\prime}(\omega)$ remains unchanged. By contrast, with the tax, the warm glow utility $\omega\left[x_{1}^{\tau}-x_{0}^{\tau}\right]=\omega^{2} / \gamma$ is constant. Green consumers are then more likely to prefer the tax when the environmental target $X$ increases.

Overall, if the green consumers' willingness to pay for greener goods $\omega$ is not too high, all consumers prefer the tax even though it entails a lower material welfare than the standard. This relative preference for the tax increases with the degree of competition for the green good (i.e., lower $\theta$ ) and with the target $X$. Also, a necessary condition for consumers to favor

a tax to the standard is that the latter be inefficient, in the sense of entailing the supply of products with heterogeneous marginal abatement costs.

This section has assumed that the target $X$ is exogenously set. We now turn to the endogeneization of this target by majority voting over, respectively, the standard and the tax.

\section{Political economy}

\subsection{Collective choice of an environmental standard}

We now examine the choice of the standard level $x_{0}$. We assume that voters aim at maximizing their own utility (including the warm glow component for green voters) when setting collectively the environmental policy. Recall from (13) and (14) that the neutral consumers' utility is given by

$$
U_{n}^{S}\left(x_{0}, x_{1}^{S}\right)=v-c\left(x_{0}\right)+b(X) \text { if } x_{0}<x_{1}^{S}
$$

and by

$$
U_{n}^{S}\left(x_{0}, x_{0}\right)=v-c\left(x_{0}\right)+b\left(x_{0}\right) \text { if } x_{0} \geq x_{1}^{S}
$$


with $x_{1}^{S}=c^{\prime-1}(\omega)$ following equation (2), and with $X=\alpha x_{1}^{S}+(1-\alpha) x_{0}$ resulting endogenously from the choice of $x_{0}$. Likewise, recall from (13) and (15) that green consumers' utility is given by

$$
U_{g}^{S}\left(x_{0}, x_{1}^{S}\right)=v+(1-\theta) \omega\left[x_{1}^{S}-x_{0}\right]-\theta c\left(x_{0}\right)-(1-\theta) c\left(x_{1}^{S}\right)+b(X) \text { if } x_{0}<x_{1}^{S},
$$

and by

$$
U_{g}^{S}\left(x_{0}, x_{0}\right)=v-c\left(x_{0}\right)+b\left(x_{0}\right) \text { if } x_{0} \geq x_{1}^{S}
$$

Comparing neutral and green consumers' utility function, we obtain that they are identical when $x_{0} \geq x_{1}^{S}$ (homogeneous good) or when $\theta=1$ (monopoly green producer), while $U_{n}^{S}\left(x_{0}, x_{1}^{S}\right)<U_{g}^{S}\left(x_{0}, x_{1}^{S}\right)$ otherwise. ${ }^{21}$ In the latter case, green firms differentiate themselves by offering a pricier product, but capture only a fraction of the additional (warm glow) surplus from green consumers when $\theta<1$.

We first look sequentially at the most-preferred standard with, respectively, homogeneous and heterogeneous goods, before turning to the standard maximizing overall utility.

With homogeneous goods (i.e. $x_{0} \geq x_{1}^{S}$ ), the utility-maximizing standard value is the same for both types of voters, and corresponds to the environmental quality $x^{F B}$ that maximizes material welfare. This level equalizes the marginal benefit to the marginal cost of the standard,

$$
b^{\prime}\left(x^{F B}\right)=c^{\prime}\left(x^{F B}\right)
$$

This is the preferred standard when a single good is supplied, which occurs when $\omega<c^{\prime}\left(x^{F B}\right)$.

With heterogeneous goods (i.e. $x_{0}<x_{1}^{S}$ ), the utility of neutral consumers in (18) peaks

\footnotetext{
${ }^{21}$ Since green consumers can guarantee themselves at least the utility level attained by neutral ones by buying good $x_{0}$ at price $p_{0}$.
} 
at a standard value denoted by $x_{0 n}^{S V}$ and defined by the following first-order condition (FOC):

$$
c^{\prime}\left(x_{0 n}^{S V}\right)=(1-\alpha) b^{\prime}\left(\alpha x_{1}^{S}+(1-\alpha) x_{0 n}^{S V}\right)
$$

Compared to (22), the marginal benefit is deflated by $1-\alpha$ because, with two environmental qualities $x_{0 n}^{S V}$ and $x_{1}^{S}$, increasing the standard only affects the contribution of neutral consumers to environmental protection $X=\alpha x_{1}^{S}+(1-\alpha) x_{0 n}^{S V}$. Note that the chosen standard is always strictly positive because $x_{0 n}^{S V}=0$ would imply that $b^{\prime}\left(X^{S V}\right)=0$, a contradiction with our assumption that $b^{\prime}()>$.0 .

We now turn to the green voters, where (20) peaks at a standard value denoted by $x_{0 g}^{S V}$ and defined by the following FOC:

$$
\omega+\theta\left[c^{\prime}\left(x_{0 g}^{S V}\right)-\omega\right]=(1-\alpha) b^{\prime}\left(\alpha x_{1}^{S}+(1-\alpha) x_{0 g}^{S V}\right)
$$

The marginal benefit from raising the standard is the same for green and neutral voters (same RHS of (23) and (24)) but the marginal costs differ. When raising the standard, green voters lose at the margin some warm glow ( $\omega$ in the LHS of (24)) and face a variation in the price for the green good $x_{1}$ (the second term on the LHS of (24)). This price variation is proportional to the degree of market power of the green firms, $\theta$, and is thus nil in the case of perfect competition. With market power, the price of the green good $p_{1}$ is affected in two opposite directions by an increase in $x_{0}$ : (i) $p_{1}$ increases because it is based in part on the cost of providing the brown good, $c\left(x_{0}\right)$, which increases, but (ii) $p_{1}$ decreases because a larger value of $x_{0}$ decreases the warm glow enjoyed by green consumers, and thus the ability of the green firms to post a mark-up over their costs. Since $x_{0}<x_{1}^{S}$ implies that $c^{\prime}\left(x_{0}\right)<c^{\prime}\left(x_{1}^{S}\right)=\omega$, the term into brackets in the LHS of $(24)$ is negative, so that the net effect of $x_{0}$ on $p_{1}$ is always negative. 
We can reformulate the LHS of (24) as

$$
\theta c^{\prime}\left(x_{0 g}^{S V}\right)+(1-\theta) \omega
$$

and comparing it to the LHS of (23), we obtain the rather counter-intuitive result that green voters prefer a lower standard $x_{0}$ than neutral voters, since their marginal cost of a higher standard is larger than for neutral voters (while the marginal benefit is the same). ${ }^{22}$ This result is driven by the loss of warm glow as the standard increases, which is only partially compensated by the price reduction (except in the case of limit pricing where the two effects cancel out so that consumers are unanimous in their choice of $\left.x_{0}^{S}\right)$.

Finally, applying the implicit function theorem on (23) and (24) shows that both $\alpha$ and $\omega$ decrease the marginal benefit from the standard (through a higher environmental quality of the green good for $\omega$, and through a higher proportion of agents consuming this good for $\alpha$ ), while $\omega$ also increases the marginal cost of the standard for the green voters, and so decrease $x_{0 n}^{S V}$ and $x_{0 g}^{S V}$. Similarly, the degree of competition $\theta$ impacts the preferred standard of green voters. A higher $\theta$ decreases the LHS of (24) by increasing the weight of the negative term into brackets, thus increasing $x_{0 g}^{S V}$. As $\theta$ increases, green firms capture a larger fraction of the warm glow effect, so that the decrease in warm glow due to a larger standard is less costly to green voters.

We have thus obtained the following proposition.

Proposition 5 When products are differentiated on their environmental quality, both types of consumers prefer the same standard $x_{0 n}^{S V}$ under monopoly limit pricing $(\theta=1)$, while green consumers prefer a lower standard than neutral consumers $\left(x_{0 g}^{S V}<x_{0 n}^{S V}\right)$ for all other degrees of competition $(\theta<1)$. The chosen standards $x_{0 n}^{S V}$ and $x_{0 g}^{S V}$ are lower than when goods are homogeneous, and decrease with both $\alpha$ and $\omega$. Furthermore $x_{0 g}^{S V}$ increases with $\theta$.

\footnotetext{
${ }^{22}$ More precisely, we have that $x_{0 g}^{S V}<x_{0 n}^{S} V$ provided that $x_{0 n}^{S V}<x_{1}^{S}$-i.e., when $\omega$ is large enough that the goods are differentiated at equilibrium.
} 
We now study under what circumstances voters prefer either a standard generating a single good with quality $x_{0}=x^{F B}$ or rather a lower standard $\left(x_{0 j}^{S V}\right.$ for type $\left.j=\{n, g\}\right)$ inducing product differentiation along the environmental quality dimension.

Let $\tilde{\omega}_{j}$ be the unique value of $\omega$ equalizing type $j=\{n, g\}$ 's consumer utility with an homogeneous good of environmental quality $x^{F B}$ with heterogeneous goods of qualities $x_{0 j}^{S V}$ and $x_{1}^{S}$. More precisely, we denote by $\tilde{\omega}_{n}$ the unique value of $\omega$ such that

$$
b\left(\alpha x_{1}^{S}+(1-\alpha) x_{0 n}^{S V}\right)-c\left(x_{0 n}^{S V}\right)=b\left(x^{F B}\right)-c\left(x^{F B}\right)
$$

with $x_{1}^{S}, x_{0 n}^{S V}$ and $x^{F B}$ defined by (2), (23) and (22) respectively. Similarly, let $\tilde{\omega}_{g}$ be the unique value of $\omega$ such that:

$$
b\left(\alpha x_{1}^{S}+(1-\alpha) x_{0 g}^{S V}\right)+(1-\theta) \omega\left[x_{1}^{S}-x_{0 g}^{S V}\right]-\theta c\left(x_{0 g}^{S V}\right)-(1-\theta) c\left(x_{1}^{S}\right)=b\left(x^{F B}\right)-c\left(x^{F B}\right)
$$

with $x_{0 g}^{S V}$ defined by (24).

We establish the following proposition, proved in Appendix D.

Proposition 6 Type $j=\{n, g\}$ 's consumers vote for the standard $x^{F B}$ that maximizes material welfare with homogeneous goods if $\omega<\tilde{\omega}_{j}$ and for a lower standard $x_{0 j}^{S V}<x^{F B}$ that generates product differentiation if $\omega>\tilde{\omega}_{j}$. The threshold $\tilde{\omega}_{j}$ decreases with $\alpha$, and $\tilde{\omega}_{g}<\tilde{\omega}_{n}$.

The citizens' choice of standard depends on green consumers' willingness to pay for environmental quality. If $\omega$ is low, the green version of the good is not supplied. All citizens vote for the same standard level maximizing their material welfare. Environmental protection is at the efficient level equalizing marginal cost and benefit of the standard. All the benefit from production goes to consumers.

When $\omega$ reaches a threshold level, the majority of voters prefer a standard lower than the 
material welfare-maximizing one, and goods of differentiated qualities are produced. ${ }^{23}$ Neutral voters free ride on the higher quality of the good consumed by green voters, and green voters lower the standard to enjoy a lower price and more warm glow, with only a fraction of this additional utility captured by green firms. ${ }^{24}$ Lemmas 1 and 2 in the proof of Proposition 6 imply that $x_{1}^{S}<x^{F B}$ for this threshold level of $\omega$. The switch towards a new majority voting equilibrium then occurs discontinuously, with a decrease in the environmental quality of both goods (compared with $x_{0}^{S}=x^{F B}$ ) which reduces overall environmental protection $X$. In other words, the environmental quality decreases discontinuously at the precise point where the green good is supplied.

As the level of green consumerism $\omega$ increases beyond this threshold, the environmental quality of the green good improves while the standard becomes laxer. Environmental protection $X$ improves driven by the demand for environmental quality by green consumers, although it is still under-provided. In contrast to the case of homogeneous goods, the standard fails to fix the environmental and market power market failures.

Green consumerism then has a negative impact on the environment except when the warmglow parameter $\omega$ is high enough that the level of environmental protection with product differentiation $X^{S V}$ exceed the one with homogeneous environmental quality $x^{F B} .^{25}$

\footnotetext{
${ }^{23}$ This threshold is $\tilde{\omega}_{n}$ if $\alpha<1 / 2$ and $\tilde{\omega}_{g}$ otherwise.

${ }^{24}$ The intuition for the impact of $\alpha$ on the threshold $\tilde{\omega}_{j}$ is that the utility with differentiated good increases with $\alpha$ (thanks to a better environmental quality for any given standard) while the utility with a single good of quality $x^{F B}$ is unaffected, so that voters prefer $x_{0 j}^{S V}<x_{1}^{S}$ (rather than $x_{0}=x^{F B}$ ) for a lower value of $\omega$ when $\alpha$ increases. Green voters switch from the $x^{F B}$ standard to the lower one they most-prefer for a lower value of $\omega$ than neutral voters, because this sub-optimal standard allows them to enjoy more warm glow, with only a fraction of the latter captured by the green firms.

${ }^{25}$ Indeed as $\omega$ tends toward infinity, $x_{0 n}^{S V}$ tends toward 0 (see (23)), so that $X$ tends toward $\alpha x_{1}^{S}$ which tends toward infinity as seen from (2).
} 


\subsection{Collective choice of the environmental tax}

We now characterize the preferred tax rate for both types of consumers, using the superscript $\tau V$. We consider first neutral consumers. Under Assumption 1, since $x_{1}^{\tau}-x_{0}^{\tau}=\omega / \gamma$, maximizing the neutral consumers' utility defined in (16) with respect to $\tau$ yields ${ }^{26}$

$$
c^{\prime}\left(x_{0 n}^{\tau V}\right)+\alpha \omega=b^{\prime}\left(\alpha x_{1 n}^{\tau V}+(1-\alpha) x_{0 n}^{\tau V}\right)
$$

The left-hand term is the marginal cost of increasing environmental quality through a higher tax while the right-hand term is the marginal benefit. The cost to consumers is twofold: higher production costs and more tax revenue captured by the green firms.

As for the green consumers, whose utility is given by (17), it is important to note that the warm-glow utility $\omega\left[x_{1}^{\tau}-x_{0}^{\tau}\right]=\omega^{2} / \gamma$ does not vary with the tax rate. Moreover, the green consumers' net tax transfer in (17) can be expressed as $\tau\left[\theta x_{0}^{\tau}+(1-\theta) x_{1}^{\tau}-X\right]=$ $\tau(1-\alpha-\theta)\left(x_{1}^{\tau}-x_{0}^{\tau}\right)=\tau(1-\alpha-\theta) \omega / \gamma$ under Assumption 1.

Maximizing the green consumers' utility with respect to $\tau$, we obtain the following FOC:

$$
\theta c^{\prime}\left(x_{0 g}^{\tau V}\right)+(1-\theta) c^{\prime}\left(x_{1 g}^{\tau V}\right)=b^{\prime}\left(\alpha x_{1 g}^{\tau V}+(1-\alpha) x_{0 g}^{\tau V}\right)+(1-\alpha-\theta) \omega
$$

The left-hand term is the marginal cost of increasing environmental quality by taxing more while the right-hand term includes the marginal benefit of a better environment and the net marginal transfer from the tax system. Both the marginal cost and the net marginal transfer depend on the degree of competition $\theta$.

It turns out that, under Assumption 1, since $c^{\prime}(X)=\gamma X=\tau+\alpha \omega$ (see equation (33) in Appendix C), the two FOCs (27) and (28) are identical and such that $c^{\prime}\left(X_{j}^{\tau V}\right)=b^{\prime}\left(X_{j}^{\tau V}\right)$ where $X_{j}^{\tau V}=\alpha x_{1 j}^{\tau V}+(1-\alpha) x_{0 j}^{\tau V}$ for $j=n, g$. Hence $X_{j}^{\tau V}=x^{F B}$ for $j=n, g$ by definition of

\footnotetext{
${ }^{26}$ We assume for the moment an interior solution. See the discussion after Proposition 7 for the case where $\omega$ is high enough that $\tau=0$ at the equilibrium.
} 
$x^{F B}$ in (22). We have then proved the following proposition.

Proposition 7 Assume that Assumption 1 holds. All consumers vote for the same tax rate implementing the aggregate environmental protection level that maximizes material welfare, $x^{F B}$, with heterogeneous qualities $x_{0}^{\tau}<x^{F B}<x_{1}^{\tau}$.

The unanimity-chosen tax level $\tau^{V}$ decentralizes the material welfare-maximizing environmental protection level, but with productive inefficiencies since $x_{0}$ is set "too low" and $x_{1}$ "too high". These inefficiencies increase with the level of green consumerism $\omega$, since $x_{1}^{\tau}-x_{0}^{\tau}=w / \gamma$. Note also from (33) in Appendix $\mathrm{C}$ that $\tau^{V}=\gamma x^{F B}-\alpha \omega$, and is thus decreasing in both the level and share of green consumerism, $\omega$ and $\alpha$ respectively, as environmental protection relies more on the green consumers' behavior. Actually, if $\omega \geq \gamma x^{F B} / \alpha$, the implemented tax is nil. Brown firms make no abatement effort $\left(x_{0}^{\tau V}=0\right)$ while the quality of the green product is driven by the demand from green consumers as with the standard $x_{1}^{\tau V}=x_{1}^{S}=\omega / \gamma$. Due to the high taste for environmental quality $\omega$, environmental protection is higher than the level that maximizes material welfare: $X^{\tau V}=\alpha \omega / \gamma>x^{F B}$. Furthermore, the unanimously-chosen tax rate $\tau^{V}$ does not depend the degree of competition $\theta$.

We summarize the main results obtained with the tax. Unlike with a standard, green consumerism is effective even when low, since two goods of different qualities are produced as soon as $\omega>0$. The preferred tax rate $\tau^{V}$ is the same for green and neutral consumers, and

implements the level of environmental protection that maximizes material welfare $x^{F B}$ but with two different levels of environmental quality $x_{0}^{\tau}<x_{1}^{\tau}$, which is inefficient.

\section{Conclusion}

Is green consumerism good for the environment? Not always. Our model sheds light on two mechanisms by which green consumerism may end up being bad for the environment. 
First, the warm glow enjoyed by green voters may generate market power for green firms. Second, the induced environmental quality differentiation at equilibrium makes it difficult for traditional instruments to correct the pollution externality in an efficient way.

Green consumerism then has two impacts on the choice between market-based (i.e., tax) and command-and-control (i.e., standard) instruments to decentralize any given pollution target. First, it makes the standard more efficient than the tax in inducing this level, reversing the usual dominance of market-based instruments. With the tax incentivizing both green and brown good producers to reduce pollution while the standard constrains only the brown good's environmental attributes, the gap between the environmental quality of the two types of good is higher with a tax. Second, green consumerism also induces consumers to prefer the inefficient tax to the standard. The environmental quality of the brown version of the good being lower with the tax, the brown good is also cheaper which benefits the neutral consumers. Green consumers enjoy a higher warm-glow utility from consuming the green good with the tax due to the higher wedge between environmental qualities. They also get back more than the tax they pay by buying the green good.

Green consumerism also affects the majority-chosen level of pollution. Both types of consumers vote for laxer standards compared to the homogeneous good case. The neutral consumers do so because they free-ride on the green consumers. The green consumers vote for an even less stringent standard to increase their warm-glow utility and to lower the price of the green good. Overall environmental quality is lower with green consumerism than without unless the willingness to pay for greener goods is strong enough that the higher environmental performance of the green goods compensates for the laxer standard. With quadratic costs, voters unanimously decentralize the efficient aggregate level of pollution, but with differentiated and thus inefficient quality levels for both goods.

Most human economic activities are polluting. Reducing their harmful impact on health, biodiversity and the climate is costly and requires imposing technological standards, banning 
the most toxic pesticides, or taxing carbon emissions. Such policies are difficult to implement because they hurt the regulated industries and their customers. Often the easy way to go for policy-makers is to rely on voluntary programs such as green labels or CSR certification to nudge producers and consumers. The hope is that enough of them react to the nudge by changing their behavior in the right direction so that the environmental problem is mitigated. We argue that, even if it is the case, this easy political solution is far from optimal. First, it is not cost-effective. Second, the reduction of pollution may be lower than in the absence of green consumerism, even if the public policy is chosen by majority voting. Overall, green consumerism may result in a collectively chosen public policy that induces too little pollution reduction, attained in an inefficient way. Green consumerism is then far from being a panacea to solve environmental issues. 


\section{A Proof of Proposition 2}

Firm 1's profit function is concave in $x_{1}$, with a maximum at $x_{1}=x_{1}^{\tau}>x_{0}^{\tau}$ when $\omega>0$. From (8), we obtain that $\lim _{x_{1} \rightarrow x_{0}^{\tau+}} \pi_{1}=\alpha \omega x_{0}^{\tau}>0$, so that $\pi_{1}$ is a fortiori positive when maximized at $x_{1}=x_{1}^{\tau}$.

\section{B Proof of Proposition 3}

Since $x_{0}^{\tau}<x_{0}^{S}<x_{1}^{S}<x_{1}^{\tau}$ and $X=\alpha x_{1}^{S}+(1-\alpha) x_{0}^{S}=\alpha x_{1}^{\tau}+(1-\alpha) x_{0}^{\tau}$, we have:

$$
\epsilon=\alpha\left(x_{1}^{\tau}-x_{1}^{S}\right)=(1-\alpha)\left(x_{0}^{S}-x_{0}^{\tau}\right)>0
$$

By convexity of the cost function, $x_{1}^{\tau}>x_{1}^{S}$ and $x_{0}^{S}>x_{0}^{\tau}$ imply respectively:

$$
\begin{aligned}
& c\left(x_{1}^{\tau}\right)-c\left(x_{1}^{S}\right)>c^{\prime}\left(x_{1}^{S}\right)\left(x_{1}^{\tau}-x_{1}^{S}\right), \\
& c\left(x_{0}^{S}\right)-c\left(x_{0}^{\tau}\right)<c^{\prime}\left(x_{0}^{S}\right)\left(x_{0}^{S}-x_{0}^{\tau}\right),
\end{aligned}
$$

Multiplying (30) by $\alpha$ and (31) by $1-\alpha$, taking the difference among the two terms and using (29), we obtain:

$$
\alpha c\left(x_{1}^{\tau}\right)+(1-\alpha) c\left(x_{0}^{\tau}\right)-\left[\alpha c\left(x_{1}^{S}\right)+(1-\alpha) c\left(x_{0}^{S}\right)\right]>\left[c^{\prime}\left(x_{1}^{S}\right)-c^{\prime}\left(x_{0}^{S}\right)\right] \epsilon
$$

The right-hand term of (32) is strictly positive because $\epsilon>0, x_{1}^{S}>x_{0}^{S}$ and $c($.$) is convex.$ Hence we obtain the desired conclusion. 


\section{Proof of Proposition 4}

We show first that, for any given environmental conservation target $X$ and degree of competition $\theta$, consumers' utilities are such that they all prefer the tax to the standard when $\omega \leq c^{\prime}(X)$. Under Assumption 1, the difference of utility between tax and standard for neutral consumers defined in (13) and (16) respectively becomes $U_{n}^{\tau}\left(x_{0}^{\tau}, x_{1}^{\tau}\right)-U_{n}^{S}(X, X)=\frac{\alpha^{2} \omega^{2}}{2 \gamma}>0$. Furthermore, since $U_{n}^{S}(X, X)=U_{g}^{S}(X, X)$ and $U_{g}^{\tau}\left(x_{0}^{\tau}, x_{1}^{\tau}\right) \geq U_{n}^{\tau}\left(x_{0}^{\tau}, x_{1}^{\tau}\right)$, where the last inequality is due to the fact that green consumers can achieve the neutral consumers' utility level by purchasing the low quality $x_{0}^{\tau}$, we have that $U_{g}^{\tau}\left(x_{0}^{\tau}, x_{1}^{\tau}\right)>U_{g}^{S}(X, X)$. Hence green consumers prefer the tax as well.

We then move to the case where $\omega>c^{\prime}(X)$. Under Assumption 1, environmental qualities defined in (2) (4), (5) and (9) are $x_{1}^{S}=\frac{\omega}{\gamma}, x_{0}^{S}=\frac{\tau}{\gamma(1-\alpha)}, x_{0}^{\tau}=\frac{\tau}{\gamma}$ and $x_{1}^{\tau}=\frac{\tau+\omega}{\gamma}$. Furthermore, with those values for $x_{0}^{\tau}$ and $x_{1}^{\tau}$ the environmental protection target $X$ can be written as

$$
X=\frac{\tau+\alpha \omega}{\gamma}
$$

Utilities defined in (14), (15), (16) and (17) are respectively:

$$
\begin{aligned}
U_{n}^{S}\left(x_{0}^{S}, x_{1}^{S}\right) & =v-\frac{\tau^{2}}{2 \gamma(1-\alpha)^{2}}+b(X), \\
U_{g}^{S}\left(x_{0}^{S}, x_{1}^{S}\right) & =v+\frac{(1-\theta) \omega}{2 \gamma}\left[\omega-\frac{2 \tau}{1-\alpha}\right]-\theta \frac{\tau^{2}}{2 \gamma(1-\alpha)^{2}}+b(X), \\
U_{n}^{\tau}\left(x_{0}^{\tau}, x_{1}^{\tau}\right) & =v-\frac{\tau}{2 \gamma}[\tau+2 \alpha \omega]+b(X), \\
U_{g}^{\tau}\left(x_{0}^{\tau}, x_{1}^{\tau}\right) & =v+\frac{1-\theta}{2 \gamma}\left[\omega^{2}+\tau^{2}\right]+\frac{\theta}{2 \gamma} \tau^{2}-\frac{\tau}{\gamma}[\tau+\alpha \omega]+b(X)
\end{aligned}
$$


We look first at neutral consumers. Utilities defined in (34) and (36) yield

$$
U_{n}^{S}\left(x_{0}^{S}, x_{1}^{S}\right)-U_{n}^{\tau}\left(x_{0}^{\tau}, x_{1}^{\tau}\right)=\frac{\tau}{2 \gamma}\left[2 \alpha \omega+\tau\left(1-\frac{1}{(1-\alpha)^{2}}\right)\right]
$$

Using (33) to substitute $\tau$ into the brackets we obtain:

$$
U_{n}^{S}\left(x_{0}^{S}, x_{1}^{S}\right)-U_{n}^{\tau}\left(x_{0}^{\tau}, x_{1}^{\tau}\right)=\frac{\tau}{2 \gamma}\left[\omega \alpha\left(1+\frac{1}{(1-\alpha)^{2}}\right)+X \gamma\left(1-\frac{1}{(1-\alpha)^{2}}\right)\right]
$$

The right-hand side of (39) is positive if $\omega$ is higher than the threshold $\tilde{\omega}_{n}(X)$ defined by:

$$
\tilde{\omega}_{n}(X) \equiv \gamma X \frac{1-(1-\alpha)^{2}}{\alpha\left(1+(1-\alpha)^{2}\right)}
$$

and is negative if $\omega$ is lower than $\tilde{\omega}_{n}(X)$. Hence, we have shown that, given $X$,neutral consumers prefer the tax if $\omega<\tilde{\omega}_{n}(X)$, and the standard otherwise. Note also that the fraction term in (40) is larger than one for all $0 \leq \alpha \leq 1$, so that $\tilde{\omega}_{n}(X)>c^{\prime}(X)=\gamma X$. Moreover, $(1-\alpha)^{2}<1$ so that $\tilde{\omega}_{n}(X)$ is increasing with $X$.

We then move to green consumers whose utilities defined in (35) and (37) yield

$$
U_{g}^{S}\left(x_{0}^{S}, x_{1}^{S}\right)-U_{g}^{\tau}\left(x_{0}^{\tau}, x_{1}^{\tau}\right)=\frac{\tau}{2 \gamma}\left[2 \omega\left(\alpha-\frac{1-\theta}{1-\alpha}\right)+\tau\left(1-\frac{\theta}{(1-\alpha)^{2}}\right)\right]
$$

Note that this utility difference is negative for $\omega=c^{\prime}(X)$ (so that $\omega=\gamma X=\alpha \omega+\tau$ resulting in $\omega=\tau /(1-\alpha))$ and is decreasing in $\omega$ if

$$
\theta<1-\alpha(1-\alpha)
$$

in which case we then have that green consumers prefer the tax to the standard for all values of $\omega$. Note that condition (42) is always satisfied if $\theta<3 / 4=\max _{\alpha \in[0,1]} 1-\alpha(1-\alpha)$. 
A necessary condition for green voters to prefer the standard is then that $\theta>1-\alpha(1-\alpha)$. Using (33) to substitute $\tau$ into the brackets we obtain:

$$
U_{g}^{S}\left(x_{0}^{S}, x_{1}^{S}\right)-U_{g}^{\tau}\left(x_{0}^{\tau}, x_{1}^{\tau}\right)=\frac{\tau}{2 \gamma}\left[\omega\left(\alpha+\frac{\alpha \theta}{(1-\alpha)^{2}}-\frac{2(1-\theta)}{1-\alpha}\right)+\gamma X\left(1-\frac{\theta}{(1-\alpha)^{2}}\right)\right]
$$

The right-hand side of (43) is positive if $\omega$ is higher than the following threshold:

$$
\tilde{\omega}_{g}(X, \theta)=\gamma X \frac{\theta-(1-\alpha)^{2}}{\theta(2-\alpha)-(1-\alpha)(2-\alpha(1-\alpha))}>0
$$

which is obviously increasing in $X$. We have

$$
\frac{\partial \tilde{\omega}_{g}(X, \theta)}{\partial \theta}=-X \frac{\gamma 2 \alpha(1-\alpha)}{[\theta(2-\alpha)-(1-\alpha)(2-\alpha(1-\alpha))]^{2}}<0
$$

and $\tilde{\omega}_{g}(X, 1)=\tilde{\omega}_{n}(X)$, so that $\tilde{\omega}_{g}(X, \theta)>\tilde{\omega}_{n}(X)>c^{\prime}(X)$ for $\theta<1$.

\section{Proof of Proposition 6}

\section{(A) Neutral voters and $x_{0 n}^{S V}$}

To show that $\tilde{\omega}_{n}$ is unique, remark that $x^{F B}$ does not depend on $\omega$, therefore the righthand side of (25) does not vary with $\omega$. On the other hand, the left-hand side increases with $\omega$ since its derivative with respect to $\omega$ equals $\alpha b^{\prime}\left(\alpha x_{1}^{S}+(1-\alpha) x_{0 n}^{S V}\right) \frac{d x_{1}^{S}}{d \omega}>0$ by making use of (23). Furthermore, $x_{1}^{S}=0$ when $\omega=0$, and therefore $b\left(\alpha x_{1}^{S}+(1-\alpha) x_{0 n}^{S V}\right)-c\left(x_{0 n}^{S V}\right)=$ $\max _{x}\{b((1-\alpha) x)-c(x)\}<\max _{x}\{b(x)-c(x)\}=b\left(x^{F B}\right)-c\left(x^{F B}\right)$ by definition of $x_{0}^{S V}$ and $x^{F B}$. For $\omega$ high enough that $x_{1}^{S}=x^{F B}$, we have $b\left(\alpha x_{1}^{S}+(1-\alpha) x_{0 n}^{S V}\right)-c\left(x_{0 n}^{S V}\right)=$ $\max _{x}\left\{b\left(\alpha x_{1}^{F B}+(1-\alpha) x\right)-c(x)\right\} \geq b\left(x^{F B}\right)-c\left(x^{F B}\right)$. Therefore $b\left(\alpha x_{1}^{S}+(1-\alpha) x_{0 n}^{S V}\right)-c\left(x_{0 n}^{S V}\right)$ is lower than $b\left(x^{F B}\right)-c\left(x^{F B}\right)$ for $\omega<\tilde{\omega}$ and becomes higher for $\omega>\tilde{\omega}$.

Note that the penultimate step in the preceding paragraph has proved the following lemma, 
which will prove useful later on in the paper.

Lemma $1 \tilde{\omega}_{n}<\omega_{1}^{S}$

We know that $x^{F B}$ is constant with $\omega$ (see (22)), that $x_{0 n}^{S V}<x^{F B}$ and is decreasing with $\omega$ (see Proposition 5), that $x_{1}^{S}$ is increasing in $\omega$ and may be lower or larger than $x^{F B}$ (since $x_{1}^{S}=0$ when $\omega=0$, while it tends towards infinity as $\omega$ grows). Hence, the following three cases exhaust all the possible ones.

Case (a) $x_{1}^{S}<x_{0 n}^{S V}<x^{F B}$

For any standard $x_{0}<x_{1}^{S}$, the utility $U_{n}\left(x_{0}\right)$, defined in the first line of (18), is increasing with $x_{0}$ up to $x_{1}^{S}$. It also increasing with $x_{0}$ above $x_{1}^{S}$-i.e., as defined in the second line of (18), up to $x_{0}=x^{F B}$. It is then decreasing above $x^{F B}$. Therefore $U_{n}\left(x_{0}\right)$ is single-peaked at $x_{0}=x^{F B}$. Note that $x_{1}^{S}<x_{0 n}^{S V}$ implies $\omega<\tilde{\omega}_{n}$ because then $b\left(\alpha x_{1}^{S}+(1-\alpha) x_{0 n}^{S V}\right)-c\left(x_{0 n}^{S V}\right)<$ $b\left(x_{0 n}^{S V}\right)-c\left(x_{0 n}^{S V}\right) \leq b\left(x^{F B}\right)-c\left(x^{F B}\right)$ where the last inequality is due to the definition of $x^{F B}$ which maximizes $b(x)-c(x)$ with respect to $x$.

Case (b) $x_{0 n}^{S V}<x^{F B}<x_{1}^{S}$

For any standard $x_{0}<x_{1}^{S}$, the utility $U_{n}\left(x_{0}\right)$-defined in the first line of (18)- is increasing up to $x_{0 n}^{S V}$ and then decreasing for $x_{0}>x_{0 n}^{S V}$. When $x_{0}>x_{1}^{S}, U\left(x_{0}\right)$ - defined in the second line of (18)- is decreasing with $x_{0}$ because $x_{0}>x^{F B}$ by assumption. Hence $U_{n}\left(x_{0}\right)$ is single-peaked at $x_{0}=x_{0 n}^{S V}$. Now $x_{1}^{S}>x^{F B}$ implies $\omega>\tilde{\omega}_{n}$ because $\max _{x} b\left(\alpha x_{1}^{S}+(1-\alpha) x\right)-c(x)>$ $b\left(\alpha x^{F B}+(1-\alpha) x^{F B}\right)-c\left(x^{F B}\right)=b\left(x^{F B}\right)-c\left(x^{F B}\right)$.

Case (c) $x_{0 n}^{S V}<x_{1}^{S}<x^{F B}$

Then $U\left(x_{0}\right)$ is double-peaked: a first peak at $x_{0}=x_{0 n}^{S V}$ on the range $\left[0, x_{1}^{S}\right]$ - when $U_{n}\left(x_{0}\right)$ is defined by the first line of (18)- and a second peak at $x_{0}=x^{F B}$ for $x_{0}$ above $x_{1}^{S}$. The two peaks have respective values $v-c\left(x_{0 n}^{S V}\right)+b\left(\alpha x_{1}^{S}+(1-\alpha) x_{0 n}^{S V}\right)$ and $v-c\left(x^{F B}\right)+b\left(x^{F B}\right)$. As shown at the beginning of the proof, the first peak is lower than the second peak when $\omega<\tilde{\omega}_{n}$ and becomes higher when $\omega>\tilde{\omega}_{n}$. 
Finally, to find the impact of $\alpha$ on $\tilde{\omega}_{n}$, we define $f(\omega, a)=b\left(\alpha x_{1}^{S}+(1-\alpha) x_{0 n}^{S V}\right)-c\left(x_{0 n}^{S V}\right)-$ $\left[b\left(x^{F B}\right)-c\left(x^{F B}\right)\right]=0$ with $f(\tilde{\omega}, \alpha)=0$. Using the envelope theorem for $x_{0 n}^{S V}$, we have $\frac{\partial \tilde{\omega}_{n}}{\partial \alpha}=$ $-\frac{\partial f(\omega, \alpha) / \partial \alpha}{\partial f(\omega, \alpha) / \partial \omega}$, with $\frac{\partial f(\omega, \alpha)}{\partial \alpha}=b^{\prime}\left(X^{S V}\right)\left(x_{1}^{S}-x_{0 n}^{S V}\right)>0$ and $\frac{\partial f(\omega, \alpha)}{\partial \omega}=b^{\prime}\left(X^{S V}\right) \alpha \frac{\partial x_{1}^{S}}{\partial \omega}>0$, so that $\tilde{\omega}_{n}$ decreases with $\alpha$.

\section{(B) Green voters and $x_{0 g}^{S V}$.}

To show that $\tilde{\omega}_{g}$ is unique, remark that $x^{F B}$ does not depend on $\omega$, therefore the righthand side of (26) does not vary with $\omega$. On the other hand, the left-hand side increases with $\omega$ since its derivative with respect to $\omega$ equals (using the envelope theorem for the choice of $\left.x_{0 g}^{S V}\right)$

$$
(1-\theta)\left(x_{1}^{S}-x_{0 g}^{S V}\right)+\frac{d x_{1}^{S}}{d \omega}\left[(1-\theta) \omega-(1-\theta) c^{\prime}\left(x_{1}^{S}\right)+\alpha b^{\prime}(X)\right]
$$

and is positive given that $c^{\prime}\left(x_{1}^{S}\right)=\omega$.

Note that we have the same three cases (a), (b) and (c) as above (replacing $x_{0 n}^{S V}$ by $x_{0 g}^{S V}$ ). Take $\omega$ such that $x_{0 g}^{S V}=x_{1}^{S}<x^{F B}$ (i.e., the value of $\omega$ such that we move from case (a) to case (b)). The utility of green voters with $x_{0 g}^{S V}$ is then equal to $b\left(x_{1}^{S}\right)-c\left(x_{1}^{S}\right)$ which is strictly lower than $b\left(x^{F B}\right)-c\left(x^{F B}\right)$. Note that this result also establishes that case (a) corresponds to values of $\omega$ that are lower than $\tilde{\omega}_{g}$.

For $\omega$ high enough that $x_{1}^{S}=x^{F B}$, we have that the utility of green voters with $x_{0}<x_{1}^{S}$ is equal to

$$
b\left(\alpha x^{F B}+(1-\alpha) x_{0}\right)+(1-\theta) \omega\left(x^{F B}-x_{0}\right)-\left[\theta c\left(x_{0}\right)+(1-\theta) c\left(x^{F B}\right)\right] .
$$

Note that $x_{0 g}^{S V}$ is precisely the value of $x_{0}$ which maximizes (46), and that (46) is equal to $b\left(x^{F B}\right)-c\left(x^{F B}\right)$ when $x_{0}=x^{F B}$. Hence, $x_{0 g}^{S V} \neq x^{F B}$ implies that (46) is larger than $b\left(x^{F B}\right)-c\left(x^{F B}\right)$. Note that this result also establishes that case (b) corresponds to values of 
$\omega$ that are higher than $\tilde{\omega}_{g}$.

Hence, we have proven (i) the uniqueness of $\tilde{\omega}_{g}$ and (ii) the following lemma.

Lemma $2 \tilde{\omega}_{g}<\omega_{1}^{S}$

We know that $x^{F B}$ is constant with $\omega$ (see (22)), that $x_{0 g}^{S V}<x^{F B}$ and is decreasing with $\omega$ (see Proposition 5), that $x_{1}^{S}$ is increasing in $\omega$ and may be lower or larger than $x^{F B}$ (since $x_{1}^{S}=0$ when $\omega=0$, while it tends towards infinity as $\omega$ grows). Hence, the following three cases exhaust all the possible ones.

Case (a) $x_{1}^{S}<x_{0 g}^{S V}$

For any standard $x_{0}<x_{1}^{S}$, the utility $U_{g}^{S}\left(x_{0}, x_{1}^{S}\right)$, defined in (20), is increasing with $x_{0}$ up to $x_{1}^{S}$. It also increasing with $x_{0}$ above $x_{1}^{S}$ - i.e., as defined in (21), up to $x_{0}=x^{F B}$. It is then decreasing above $x^{F B}$. Therefore green voters' utility is single-peaked at $x_{0}=x^{F B}$. Recall that we have already established above that $x_{1}^{S}<x_{0 g}^{S V}$ implies that $\omega<\tilde{\omega}_{g}$.

Case (b) $x_{0 g}^{S V}<x^{F B}<x_{1}^{S}$

For any standard $x_{0}<x_{1}^{S}$, the utility $U_{g}^{S}\left(x_{0}, x_{1}^{S}\right)$, defined in (20), is increasing up to $x_{0 g}^{S V}$ and then decreasing for $x_{0}>x_{0 g}^{S V}$. When $x_{0}>x_{1}^{S}, U_{g}^{S}\left(x_{0}, x_{0}\right)$ - defined in (21)- is decreasing with $x_{0}$ because $x_{0}>x^{F B}$ by assumption. Hence green voters' utility is single-peaked at $x_{0}=x_{0 g}^{S V}$. As we have seen above, $x^{F B}<x_{1}^{S}$ implies that $\omega<\tilde{\omega}_{g}$.

Case (c) $x_{0}^{S V}<x_{1}^{S}<x^{F B}$

Then green voters' utility function is double-peaked: a first peak at $x_{0}=x_{0 g}^{S V}$ on the range $\left[0, x_{1}^{S}\right]$ - when utility is defined by (20)- and a second peak at $x_{0}=x^{F B}$ for $x_{0}$ above $x_{1}^{S}$. As shown at the beginning of the proof, the first peak is lower than the second peak when $\omega<\tilde{\omega}_{g}$ and becomes higher when $\omega>\tilde{\omega}_{g}$. 
Finally, to find the impact of $\alpha$ on $\tilde{\omega}_{g}$, we define $f(\omega, a)=b(X)+(1-\theta) \omega\left[x_{1}^{S}-x_{0}\right]-$ $\theta c\left(x_{0}\right)-(1-\theta) c\left(x_{1}^{S}\right)-\left[b\left(x^{F B}\right)-c\left(x^{F B}\right)\right]=0$ with $f(\tilde{\omega}, \alpha)=0$. Using the envelope theorem for $x_{0}^{S V}$, we have $\frac{\partial \tilde{\omega}_{g}}{\partial \alpha}=-\frac{\partial f(\omega, \alpha) / \partial \alpha}{\partial f(\omega, \alpha) / \partial \omega}$. Using the envelope theorem, we obtain $\frac{\partial f(\omega, \alpha)}{\partial \alpha}=b^{\prime}\left(X^{S V}\right)\left(x_{1}^{S}-x_{0}^{S V}\right)>0, \frac{\partial f(\omega, \alpha)}{\partial \omega}>0$ (see (45)), so that $\tilde{\omega}_{g}$ decreases with $\alpha$.

\section{(C) Comparison of thresholds}

Recall that $\tilde{\omega}_{j}$ is the value of $\omega$ such that

$$
U_{j}^{S}\left(x_{0 j}^{S V}, x_{1}^{S}\right)=U_{j}^{S}\left(x^{F B}, x^{F B}\right)=v-c\left(x^{F B}\right)+b\left(x^{F B}\right), j=\{n, g\}
$$

with $x_{0 j}^{S V}$ given by (23) and (24) and with $x_{1}^{S}=c^{\prime-1}(\omega)$. The proof above has already established that (i) $U_{j}^{S}\left(x_{0 j}^{S V}, x_{1}^{S}\right)$ increases with $\omega$, (ii) $U_{g}^{S}\left(x_{0 j}^{S V}, x_{1}^{S}\right)>U_{n}^{S}\left(x_{0 j}^{S V}, x_{1}^{S}\right)$ and that the RHS of (47) is independent of $\omega$. Hence, we have that $\tilde{\omega}_{g}<\tilde{\omega}_{n}$. 


\section{References}

Aghion, Philippe, Roland Bénabou, Ralf Martin, and Alexandra Roulet. 2020. Environmental Preferences and Technological Choices: Is Market Competition Clean or Dirty?, National Bureau of Economic Research Working Paper 26921, http: //www . nber .org/papers/w26921.

Allcott, Hunt, Mullainathan, Sendhil, and Dmitry Taubinsky. 2012. Externalities, internalities, and the targeting of energy policy, National Bureau of Economic Research Working Paper 17977.

Ambec, Stefan, and Jessica Coria. 2021. The information value of environmental taxes Journal of Public Economics, 199: 104439

Ambec, Stefan, and Paul Lanoie. 2008. Does it pay to be green? A Systematic Overview, Academy of Management Perspectives, 23: 45-62.

Baron, David. 2001. Private politics, corporate social responsibility, and integrated strategy, Journal of Economics \& Management Strategy 10(1): 7-45.

Bansal, Sangeeta, and Shubhashis Gangopadhyay. 2003. Tax/subsidy policies in the presence of environmentally aware consumers. Journal of Environmental Economics and Management, 45(2), pp.333-355.

Benabou, Roland, and Jean Tirole. 2010. Individual and corporate social responsibility, Economica, 77, 1-19.

Besley, Tim, and Maitreesh Ghatak. 2007. Retailing public goods: The economics of corporate social responsibility, Journal of Public Economics, 91(9): 1645-1663.

Bezin, Emeline. 2015. A cultural model of private provision and the environment. Journal of Environmental Economics and Management, 71, pp.109-124. 
Bezin, Emeline. 2019. The economics of green consumption, cultural transmission and sustainable technological change. Journal of Economic Theory, 181, pp.497-546.

Bovenberg, A. Lans, Lawrence H. Goulder, and Mark R. Jacobsen. 2008. Costs of alternative environmental policy instruments in the presence of industry compensation requirements. Journal of Public Economics 92 (5): 1236-53.

Calveras, Aleix, Juan-José Ganuza, and Gerard Llobet. 2007. Regulation, corporate social responsibility and activism, Journal of Economics and Management Strategy, 16(3): 719-740.

Carson, Richard T., and Jacob LaRiviere. 2018. Structural uncertainty and pollution control: Optimal stringency with unknown pollution sources, Environmental and Resource Economics, 71(2), 337-355.

Cassin, Lesly, Melindi-Ghidi, Paolo, and Fabien Prieur. 2021. The impact of income inequality on public environmental expenditure with green consumerism, working paper ffhal-03146526v3

Conrad, Klaus. 2005. Price competition and product differentiation when consumers care for the environment, Environmental and Resource Economics, 31: 1-19.

Daubanes, Julien, and Jean-Charles Rochet. 2019. The rise of NGO activism, American Economic Journal: Economic Policy, 11 (4): 183-212.

Eichner, Thomas, and Rüdiger Pethig. 2020. Kantian defy the economists' mantra of uniform Pigovian emission taxes, CESifo Working Paper 8749, CESifo Munich, Germany.

Eriksson, Clas. 2004. Can green consumerism replace environmental regulation? A differentiatedproducts example, Resource and Energy Economics, 26: 281-293. 
Fleckinger, Pierre, and Matthieu Glachant. 2011. Negotiating a voluntary agreement when firms self regulate, Journal of Environmental Economics and Management, 62(1): 41-52.

Fowlie, Meredith, and Nicholas Muller. 2019. Market-based emissions regulation when damages vary across sources: What are the gains from differentiation? Journal of the Association of Environmental and Resource Economists, 6(3), 593-632.

Friedman, Milton. 1970. The social responsibility of business is to increase its profits, The New York Times September 13: 32-33.

Goodin, Robert. E. 1986. Laundering preferences. Foundations of Social Choice Theory, $75,81-86$.

Hammond, Peter J. 1988. Altruism, in the New Palgrave: a Dictionary of Economics, ed. John Eatwell, Murray Milgate, and Peter Newman, London: Macmillan Press.

Harsanyi, John C. 1995. A theory of social values an a rule utilitarian theory of morality, Social Choice and Welfare, 12: 319-344.

Heyes, Anthony, and Sandeep Kapur. 2012. Community pressure for green behavior, Journal of Environmental Economics and Management, 64(3): 197-210.

Hidrue, Michael K., George R. Parsons, Willett Kempton, and Meryl P. Gardner. 2011. Willingness to pay for electric vehicles and their attributes, Resource and Energy Economics, 33: 686-705.

Jacobsen, Mark R. 2013. Evaluating US fuel economy standards in a model with producer and household heterogeneity, American Economic Journal: Economic Policy 5 (2): $148-87$. 
Jacobsen, Mark R., Jacob LaRiviere, and Michael Price. 2017. Public good provision in the presence of heterogeneous green preferences, Journal of the Association of Environmental and Resource Economists, 4: 243-280

Kitzmueller, Markus, and Jay Shimshack. 2012. Economic perspectives on corporate social responsibility, Journal of Economic Literature 50(1): 51-84.

Kotchen, Matthew J. 2006. Green markets and private provision of public goods, Journal of Political Economy, 114(4): 816-834.

Krishnamurthy, Chandra Kiran B., and Bengt Kriström. 2015. Determinants of the PricePremium for Green Energy: Evidence from an OECD Cross-Section, Environmental and Resource Economics, 39: 68-88.

Ma, Chunbo, and Michael Burton. 2016. Warm glow from green power: Evidence from Australian electricity consumers, Journal of Environmental Economics and Management, 78: $106-120$.

Marini, Marco A., Ornella Tarolaz, and Jacques-François Thisse. 2020. Is environmentalism the right strategy to decarbonize the world?, Working Paper, CORE Université Catholique de Louvain, Belgium.

Schmidt, Klaus M., and Fabian Herweg. 2021. Prices versus quantities with morally concerned consumers, Discussion Paper 272, University of Munich, Gernmany.

Tsvetanov, Tsvetan, and Kathleen Segerson. 2014. The welfare effects of energy efficiency standards when choice sets matter Journal of the Association of Environmental and Resource Economists 1 (1): 233-71.

Weitzman, Martin. 1974. Prices versus quantities Review of Economic Studies 41:477-91. 